\title{
Unhealthy Cooking and Prevalence of Tuberculosis in Indian Women: A Case Study
}

\author{
Abha Lakshmi Singh ${ }^{*}$, Saleha Jamal \\ ${ }^{1}$ Department of Geography, Aligarh Muslim University, Aligarh, India. \\ Email: ${ }^{*}$ abhalakshmisingh@yahoo.com, salehajm@gmail.com
}

Received April 2 $2^{\text {nd }}, 2012$; revised May $3^{\text {rd }}, 2012$; accepted June $1^{\text {st }}, 2012$

\begin{abstract}
Unhealthy cooking is one of the major cause of mortality and morbidity and a risk factor for occurrence of tuberculosis among Indian women. India is the TB burden country in the world and accounts for nearly 20 percent of global burden of tuberculosis. The present study establishes the association between unhealthy cooking conditions (use of biomass fuels/chulhas, cooking in multipurpose room, Non-ventilated kitchen, living in kutcha/semi-pucca houses) and prevalence of tuberculosis in women. This study is based on primary sources of data collected through questionnaire interviews from 2101 women respondents belonging to different income categories from Aligarh city. The study examines the socio-economic characteristics, cooking conditions, monitoring of indoor air quality of different types of kitchen locations using different types of fuels. Symptomatic linkages of tuberculosis with type of fuel use, kitchen locations and house type were analysed. The results show that the women using biomass fuels/chulhas cooking in non-ventilated kitchens and multipurpose room, living in kutcha/semi pucca houses were most prone to tuberculosis.
\end{abstract}

Keywords: Tuberculosis; Indoor Air Pollution; Biomass Fuels; Unhealthy Cooking

\section{Introduction}

"The kitchen kills more than sword" [1]. One of the major causes of morbidity and mortality is indoor air pollution caused by burning of cooking fuels such as wood, agricultural residues, animal dung, coal, kerosene, LPG etc. Even today one half of the world's population, 95 per cent in poor countries [2] and more than 90 per cent households of India [3] still rely on traditional solid fuels including biomass fuels which releases 50 times more noxious pollutants (including particulate matter, carbon monoxide, nitrogen dioxide, sulphur dioxide, formaldehyde and carcinogens such as benzo (a) pyrene and benzene) hazardous to health. Traditional fuels are characterized by low combustion efficiency leading to emission of suspended particles and poisonous gases on the other hand modern fuels are characterized by high combustion efficiency and low emission of toxic pollutants.

A range of social, environmental and behavioural factors influence exposure and susceptibility to tuberculosis infection. Active tobacco smoking has been identified as a risk factor for $\mathrm{TB}$, presumably damaging immune and other protective mechanism, allowing TB infection to prosper [4-6]. The composition of tobacco smoke has many similarities to that of indoor cooking smoke from

${ }^{*}$ Corresponding author. biomass fuel [7-9] exposure to which is common in developing countries. Nearly three fourth of the Indian households (including 3 out of 10 urban and 8 out of 10 rural households) cook on traditional fuels on open fire or chulhas (u shaped open small structure made of bricks and mud) [10]. These chulhas are not energy efficient and the fuel is not completely burnt. The incomplete combustion releases hundreds of complex toxic pollutants hazardous to health. It has been estimated that Indian households using solid fuels the mean 24 hour $\mathrm{PM}_{10}$ concentration sometimes exceeds $2000 \mu \mathrm{g} / \mathrm{m}^{3}$, where $\mathrm{PM}_{10}$ refers to particulate matter with a diameter of less than or equal to $10 \mu \mathrm{m}$, these particles penetrates into the respiratory system. Cooking smoke can increase the risk of catching tuberculosis. The exposure to indoor smoke is particularly high among women because they are mainly responsible for cooking food. They are regularly exposed to high levels of pollutants emitted from cooking fuels. Therefore, an association of tuberculosis with domestic cooking fuel is plausible.

Tuberculosis (TB) is a major infectious disease that causes illness and death worldwide [11]. One third of world's population is thought to be infected with TB and new infections occur at about 1 per second [12]. India is the TB burden country in the world and accounts for nearly 20 percent of global burden of tuberculosis. Every 
year approximately 1.8 million persons develop tuberculosis and about 0.3 million people die of it. It kills more adults especially women in the most reproductive age group (15 - 45 years), than all the causes of maternal mortality combined. Nearly one third female infertility in India is caused by tuberculosis. Indian women tend to neglect their illness till they are too sick, because they are ostracised in the household and neighbourhood and they depend on others to get the necessary medical attention [13]. Keeping these aspects in mind a household survey was conducted in Aligarh city to establish the association of unhealthy cooking conditions which includes exposure different cooking fuels (biomass, LPG), cooking in different locations (in separate kitchen, in verandah, in multipurpose room and in open air), living in different house types (kutcha/semi pucca and pucca) and tuberculosis in women.

\section{Database and Methodology}

The study is mainly based on primary sources of data which were collected through household surveys with the help of questionnaire interviews. Field work was con ducted during the years 2009 and 2010. The following methods were adopted for the study,

1) For the purpose of selecting the sample, multistage stratified random sampling design was adopted. The first stage consisted of selection of city areas/wards from where the sample was to be selected. From the 70 wards of the city, 14 wards were selected from the different parts of the city ( 5 wards from the congested old part of the city; 3 wards from the new part and 6 wards from the fringe areas). In second stage 10 percent households belonging to different income groups were selected from each of the 14 wards (Figure 1). The total sample size consisted of 2101 households ( 300 from the high income group (>Rs. 25,000 per month, 620 from medium income group (Rs. 15,001 - 25,000 per month) 647 from low income group (Rs. 5001 - 15,000 per month) and 533 from very low income group ( $<$ Rs. 5000 per month) (1 US\$ = Rs. 53, 2011). From each household a woman respondents actively engaged in household/cooking work were chosen as respondents.

2) Indoor air pollutants were monitored in different cooking places (in separate kitchen, in verandah, in

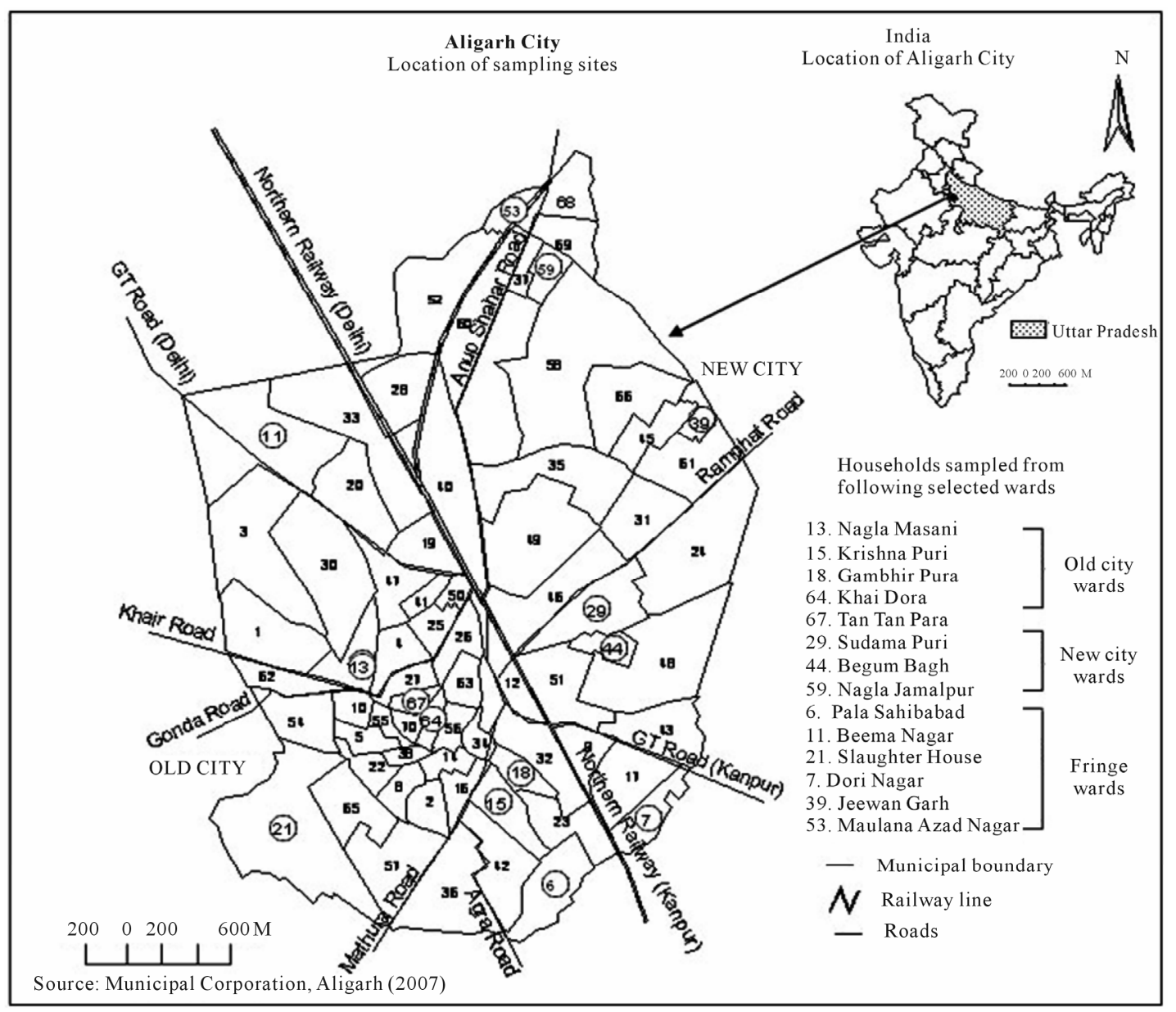

Figure 1. Location of sampling sites in Aligarh City. 
multipurpose room and on open air) and use of different domestic cooking fuels (traditional/biomass fuels, modern/LPG) to diagnose the indoor air quality. For the purpose of monitoring of SPM $\left(\mathrm{PM}_{10}, \mathrm{PM}_{2.5}\right)$, a handy sampler "Portable GRIMM Dust Monitor Series 1.109" and for monitoring gaseous pollutants $\left(\mathrm{CO}_{2}, \mathrm{CO}, \mathrm{SO}_{2}, \mathrm{NO}\right.$, $\mathrm{NO}_{2}$ ) "YES-206" and "YES-205" handy samplers were used.

3) Linkages between different type of fuels used, kitchen locations, house type, and occurrence of tuberculosis was examined. The occurrence of tuberculosis in women was assessed with the help of self reported symptoms of tuberculosis which includes persistent cough, continuous fever, phlegm, chest pain, haemoptysis and other symptoms like breathlessness, sore throat, running nose etc.

\section{Results and Discussion}

Tuberculosis has been described as a barometer of social welfare. So the information regarding the socio-economic conditions of the sampled women respondents was collected with the help of questionnaire interviews which has been presented in Table 1. Of the total sampled women respondents (2101) living in different parts of Aligarh city $\left(27^{\circ} 53^{\prime} \mathrm{N}\right.$ latitude and $78^{\circ} 4^{\prime} \mathrm{E}$ longitude, a medium sized city located in the fertile Gangetic plain of North India), 14 percent were from high income group, 30 per cent from medium, 31 per cent from low and 25 per cent from very low. Income determines man's way of living, type of house, place of cooking and fuel used for cooking.

Of the total sample, 90 percent were in the reproductive age group ( 15 to 45 years) and were married, half of them were educated and only 23 percent were working. Half of the respondents were coming from nuclear families (spouse and children only) while rest coming from joint families (spouse, children, parents and families of other members). Nearly 23 percent reported of having more than 10 family members and 68 percent had 5 to 10 members indicating large family size (Tables $\mathbf{1}(\mathbf{a})$ and (b)). The type of house (kutcha/pucca or semi-pucca), number of rooms the household occupies $(1,2,3+)$ and floor space per person in sleeping room (less than $10 \mathrm{sq} . \mathrm{ft}, 10$ to 20 , more than 20 sq.ft) also reflects the socio-economic background of the occupants. Table 1(c) shows the quality of housing occupied by the respondents, 67 percent lived in pucca houses (made of bricks, concrete, tiles asbestos etc.) and 33 percent lived in kutcha (made of mud, grass, leaves, thatched, bamboo etc.) and semipucca houses. About 39 percent lived in just one room and 40 percent were having less than 10 sq. $\mathrm{ft}$. sleeping place. This again indicates crowding in homes.

Income-wise socio-economic characteristics of the sam- pled women respondents is presented in Tables 1(a)-(c) show the plight of the lower income women respondents. Most of them were coming from joint families comprising of 5 to 10 and more than 10 members. Most of them were uneducated ( 88 percent) and unemployed (67 percent). Regarding their housing condition it was observed that mostly (64 percent) they were living in sub-standard kutcha/semi-pucca houses, having leaky thatched roofs, with mud or brick walls. Kutcha roof retains the smoke inside the room for longer duration. Most (94 percent) of the households occupied one room and had less than 10 sq. $\mathrm{ft}$. (77 percent) and 10 to 20 sq. $\mathrm{ft}$. (22 percent) floor space per person in the sleeping room. This shows crowding/congestion in their homes because of large family size and more than one family living in one room house. This will aggravate the occurrence of diseases especially tuberculosis which is a contagious diseases.

\section{Cooking Conditions: Place of Cooking, Type of Fuel/Stove Used and Its Exposure}

Tables 2(a), 2(b) give information regarding the place of cooking (in separate kitchen, in verandah, in multipurpose room, in open air), ventilation at cooking locations, type of fuel/stove used for cooking (traditional (biomass fuels/chulhas), modern (LPG/LPG stoves)) and exposure to smoke and heat.

Regarding the place of cooking (Table 2(a)), 53-percent reported that they do not have separate kitchen instead they cook indoors in verandah ( 25 percent), in a multipurpose-room (14 percent) and in open spaces (14 percent). About 47 percent households were cooking food in a separate kitchen (all the high income, 81 percent of medium, 28 percent of low and 2 percent of the very low income). Thus it was observed that it was the lower income women who were cooking either in the verandah (40 percent very low, 32 percent low), multipurpose room (31 percent very low, 19 percent of low) and in open space (27 percent very low, 21 percent low). Most of the lower income women (78 percent of very low and 43 percent of low) reported of absence of ventilation at cooking locations.

The results of questionnaire survey (Table 2(a)) indicates a fuel transition as one moves from poor to wealthy households which reveals that women belonging to lower income group tend to use the traditional biomass fuels (agricultural residues/twigs, wood, dung cake, kerosene, coal, etc) and traditional stoves (chulhas, kerosene stoves etc.) in higher percentages (97 percent very low and 79 percent low). Although the traditional/biomass fuels are not clean and efficient, still they prefer it because of its affordability and local availability. The entire higher income group and 80 percent of the medium group 
Table 1. Socio-economic characteristics (in percentages) of the sampled women respondents. (a) Age, marital status, family type and size; (b) Educational and occupational status; (c) House type and crowding.

(a)

\begin{tabular}{cccccccccccc}
\hline \multirow{2}{*}{ Income group } & $\begin{array}{c}\text { No. of sampled } \\
\text { WR/HH }\end{array}$ & \multicolumn{3}{c}{ Age in years } & \multicolumn{3}{c}{ Marital status } & \multicolumn{2}{c}{ Family type } & \multicolumn{3}{c}{ Number of family members } \\
\cline { 3 - 11 } & $15-24$ & $25-34$ & $35-44$ & $>45$ & Married & Nuclear & Joint & $<5$ & $5-10$ & $>10$ \\
\hline High & 301 & 5.98 & 65.78 & 22.26 & 5.98 & 96.68 & 56.81 & 43.19 & 21.99 & 56.74 & 21.27 \\
Medium & 620 & 16.29 & 50.16 & 25.32 & 8.23 & 88.87 & 52.74 & 47.26 & 9.26 & 68.71 & 22.03 \\
Low & 647 & 16.54 & 44.36 & 25.19 & 13.91 & 89.64 & 46.68 & 53.32 & 3.40 & 72.18 & 24.42 \\
Very low & 533 & 20.64 & 45.97 & 20.64 & 12.76 & 88.56 & 47.65 & 52.35 & 4.13 & 72.45 & 23.42 \\
\multicolumn{1}{c}{ Total } & 2101 & 15.99 & 49.55 & 23.66 & 10.80 & 90.15 & 50.97 & 49.03 & 9.70 & 67.52 & 22.78 \\
\hline
\end{tabular}

(b)

\begin{tabular}{|c|c|c|c|c|c|c|c|c|c|c|}
\hline \multirow{2}{*}{ Income group } & \multirow{2}{*}{$\begin{array}{l}\text { No. of sampled } \\
\text { WR/HH }\end{array}$} & \multirow{2}{*}{$\frac{\text { Educational statı }}{\text { Educated }}$} & \multicolumn{7}{|c|}{ Levels of education } & \multirow{2}{*}{$\frac{\text { Occupational status }}{\text { Employed }}$} \\
\hline & & & $\mathrm{P}$ & M & HS & IM & G & PG & Pr. & \\
\hline High & 301 & 96.01 & 1.04 & 8.65 & 13.15 & 20.42 & 23.88 & 20.76 & 12.11 & 7.31 \\
\hline Medium & 620 & 71.94 & 6.28 & 15.02 & 18.61 & 18.39 & 20.63 & 15.70 & 5.38 & 15.32 \\
\hline Low & 647 & 22.41 & 42.07 & 38.62 & 15.17 & 2.76 & 1.38 & - & - & 27.05 \\
\hline Very low & 533 & 12.2 & 72.31 & 20.00 & 7.69 & - & - & - & - & 36.02 \\
\hline Total & 2101 & 44.98 & 14.71 & 17.04 & 15.66 & 15.34 & 17.25 & 13.76 & 6.24 & 23.04 \\
\hline
\end{tabular}

(c)

\begin{tabular}{ccccccccccc}
\hline \multirow{2}{*}{$\begin{array}{c}\text { Income } \\
\text { group }\end{array}$} & $\begin{array}{c}\text { No. of } \\
\text { sampled HH }\end{array}$ & \multicolumn{3}{c}{ House type } & \multicolumn{2}{c}{ Number of rooms household occupies } & \multicolumn{3}{c}{ Floor space/per person/in the sleeping room } \\
\cline { 3 - 10 } & Kutcha & Pucca & Semi pucca & 1 & 2 & $3+$ & $<10$ sq. ft. & $10-20$ sq. ft. & $>20$ sq. ft. \\
\hline High & 301 & - & 100.00 & - & - & 15.90 & 84.10 & - & 14.68 & 85.32 \\
Medium & 620 & - & 90.16 & 9.84 & 11.50 & 49.20 & 39.30 & 20.81 & 44.68 & 34.51 \\
Low & 647 & 13.14 & 56.11 & 30.75 & 50.80 & 40.40 & 5.60 & 61.56 & 38.44 & - \\
Very low & 533 & 26.08 & 35.27 & 38.65 & 94.10 & 5.90 & - & 77.74 & 22.26 & - \\
Total & 2101 & 10.66 & 67.17 & 22.17 & 39.10 & 27.85 & 32.22 & 40.02 & 30.02 & 29.96 \\
\hline
\end{tabular}

WR-Women respondents; HH-Household; Source: Based on field survey, 2010-2011.

reported of using modern cooking fuels (LPG, electricity) and modern stoves (LPG stoves, heaters). Some of the medium income (13 percent) and lower income group (7 percent) reported of using both traditional biomass and modern fuels/stoves for cooking purpose in order to save money or at the time of emergency when there is shortage of gas cylinders or at times of power cuts. Women who spend long hours in kitchen (more than 5 hours; 36 percent very low, 30 percent low) are exposed to the pollutants emitted from cooking fuel for longer duration and were the main sufferers. Sample survey revealed that more than half of the women respondents (53 percent) were exposed to smoke for 1 to 2 or more than two hours, of which the very low (98 percent) and low (82 percent) income respondents are at very high risk. Similarly, exposure to open flames/fire and heat was observed to be higher among the lower income strata, nearly all the very low and low income women respondents were exposed to fire/hear for 2 to 4 or more than 4 hours per day. About 67 percent of the medium income women were exposed to fire/heat for 2 to 4 or more than 4 hours per day while more than half of the higher income women were exposed to heat/fire for less than 2 hours per day. 
Table 2. Cooking conditions, type of fuel/stoves used and exposure to smoke and heat (in percentages). (a) Place of cooking, ventilation at location of cooking; (b) Type of fuel used and its exposure.

(a)

\begin{tabular}{|c|c|c|c|c|c|c|c|}
\hline \multirow{2}{*}{$\begin{array}{l}\text { Income } \\
\text { group }\end{array}$} & \multirow{2}{*}{$\begin{array}{l}\text { Number of } \\
\text { sampled HH }\end{array}$} & \multicolumn{4}{|c|}{ Place of cooking food } & \multirow{2}{*}{$\begin{array}{l}\text { Kitchen ventilation } \\
\text { Absence of kitchen } \\
\text { ventilation }\end{array}$} & \multirow{2}{*}{$\begin{array}{c}\text { Duration of cooking } \\
>5 \text { hours per day }\end{array}$} \\
\hline & & $\begin{array}{c}\text { Separate } \\
\text { indoor Kitchen }\end{array}$ & $\begin{array}{l}\text { Indoor kitchen } \\
\text { in verandah }\end{array}$ & $\begin{array}{l}\text { Indoor kitchen in } \\
\text { multipurpose room }\end{array}$ & $\begin{array}{l}\text { Open air } \\
\text { kitchen }\end{array}$ & & \\
\hline High & 301 & 100.00 & - & - & - & - & 17.94 \\
\hline Medium & 620 & 80.97 & 15.97 & 1.45 & 1.61 & 3.86 & 22.74 \\
\hline Low & 647 & 28.13 & 31.68 & 18.70 & 21.49 & 42.9 & 29.52 \\
\hline Very low & 533 & 1.69 & 40.15 & 30.77 & 27.39 & 77.74 & 36.20 \\
\hline Total & 2,101 & 47.31 & 24.65 & 13.99 & 14.05 & 24.99 & 26.66 \\
\hline
\end{tabular}

(b)

\begin{tabular}{|c|c|c|c|c|c|c|c|c|c|c|}
\hline \multirow{2}{*}{$\begin{array}{l}\text { Income } \\
\text { group }\end{array}$} & \multirow{2}{*}{$\begin{array}{c}\text { Number of } \\
\text { sampled WR/HH }\end{array}$} & \multicolumn{3}{|c|}{ Use of fuels/stoves } & \multicolumn{3}{|c|}{ Time of exposure to indoor smoke } & \multicolumn{3}{|c|}{ Time of exposure to fire/heat } \\
\hline & & Traditional/biomass & Modern & Both & $<1 \mathrm{hr}$ & $1-2$ hrs. & $>2$ hrs. & $<2$ hrs. & $2-4$ hrs. & $>4$ hrs. \\
\hline High & 301 & - & 100.00 & - & 100.00 & - & - & 51.62 & 43.06 & 5.32 \\
\hline Medium & 620 & 6.45 & 79.84 & 13.71 & 90.16 & 8.23 & 1.61 & 32.58 & 47.58 & 19.84 \\
\hline Low & 647 & 79.44 & 13.14 & 7.42 & 17.93 & 56.11 & 25.96 & 1.85 & 74.81 & 23.34 \\
\hline Very low & 533 & 96.62 & 3.38 & - & 2.07 & 50.09 & 47.84 & - & 74.86 & 25.14 \\
\hline Total & 2,101 & 50.88 & 42.79 & 6.33 & 46.98 & 32.41 & 20.61 & 20.51 & 59.31 & 20.18 \\
\hline
\end{tabular}

WR-Women respondent; HH-Household; Source: Based on field survey, 2010-2011.

\section{Monitoring Indoor Air Pollution}

Indoor air pollutants were monitored and the results are presented in Table 3 which shows that the concentrations of SPM and gaseous pollutants at various locations of cooking (separate kitchen (with/without ventilation), in verandah, in multipurpose room and in open air) depends on the type of kitchen and different types of cooking fuels (biomass, LPG) used. Personal exposure to SPM while cooking with traditional/biomass were greatest in open air cooking where it ranged between $380.90 \mu \mathrm{g} \cdot \mathrm{m}^{-3}$ for $\mathrm{PM}_{10}$ and $249.35 \mu \mathrm{g} \cdot \mathrm{m}^{-3}$ for $\mathrm{PM}_{2.5}$ followed by cooking with biomass in verandah, $122.91 \mu \mathrm{g} \cdot \mathrm{m}^{-3}$ which ranged between $264.81 \mu \mathrm{g} \cdot \mathrm{m}^{-3}$ for $\mathrm{PM}_{10}$ and 128.18 $\mu \mathrm{g} \cdot \mathrm{m}^{-3}$ for $\mathrm{PM}_{2.5}$. The concentration at various locations of cooking with LPG depended on the type of kitchen. The mean exposure of SPM while cooking with LPG in verandah was recorded $167.7 \mu \mathrm{g} \cdot \mathrm{m}^{-3}$ for $\mathrm{PM}_{10}$ and $111.14 \mu \mathrm{g} \cdot \mathrm{m}^{-3}$ for $\mathrm{PM}_{2.5}$, in separate kitchen with ventilation was recorded $122.91 \mu \mathrm{g} \cdot \mathrm{m}^{-3}$ for $\mathrm{PM}_{10}$ and 67.09 $\mu \mathrm{g} \cdot \mathrm{m}^{-3}$ for $\mathrm{PM}_{2.5}$ followed by $118.08 \mu \mathrm{g} \cdot \mathrm{m}^{-3}$ for $\mathrm{PM}_{10}$ and $50.94 \mu \mathrm{g} \cdot \mathrm{m}^{-3}$ for $\mathrm{PM}_{2.5}$ in multipurpose room and $112.94 \mu \mathrm{g} \cdot \mathrm{m}^{-3}$ for $\mathrm{PM}_{10}$ and $54.65 \mu \mathrm{g} \cdot \mathrm{m}^{-3}$ for $\mathrm{PM}_{2.5}$ in separate kitchen without ventilation. The highest concentration of gaseous pollutant was found in kitchen using biomass fuel for cooking i.e. $3.34 \mathrm{ppm}, 509.71 \mathrm{ppm}, 0.07$ ppm, 0.10 ppm, 0.03 ppm for $\mathrm{CO}, \mathrm{CO}_{2}, \mathrm{SO}_{2}, \mathrm{NO}, \mathrm{NO}_{2}$ followed by in non-ventilated kitchen using LPG which was recorded $0.9 \mathrm{ppm}, 401.71 \mathrm{ppm}, 0.02 \mathrm{ppm}, 0.04 \mathrm{ppm}$, $0.02 \mathrm{ppm}$ for $\mathrm{CO}, \mathrm{CO}_{2}, \mathrm{SO}_{2}, \mathrm{NO}, \mathrm{NO}_{2}$ and ventilated kitchen which was recorded to be $0.89 \mathrm{ppm}, 395.71 \mathrm{ppm}$, $0.02 \mathrm{ppm}, 0.04 \mathrm{ppm}, 0.02 \mathrm{ppm}$ for $\mathrm{CO}, \mathrm{CO}_{2}, \mathrm{SO}_{2}, \mathrm{NO}$, $\mathrm{NO}_{2}$.

The concentration of SPM was higher in open air cooking places, in verandah, in separate kitchen with ventilation because a great portion of particulates originating from the outdoor air enters the indoor environment but due to open space the concentration level soon gets dissipated in atmospheric air but the concentration of SPM in non-ventilated kitchen and in multipurpose room gets concentrated and remain indoor for longer duration thus increasing exposure time. The study reveals that the concentration of indoor pollutants especially particulate matter, carbon dioxide, carbon monoxide, sulphur dioxide, nitrogen oxide, nitrogen dioxide is maximum when cooking is done using traditional/biomass fuels/chulhas in a multipurpose room and in non-ventilated kitchens.

If we compare Table 2 (showing the cooking conditions, place of cooking, ventilation at cooking locations, 
Table 3. Mean concentrations of SPM and gaseous pollutants in different types of kitchen locations using different types of fuels.

\begin{tabular}{|c|c|c|c|c|c|}
\hline \multirow{2}{*}{ Type of kitchen with different fuel use } & \multicolumn{5}{|c|}{ Mean exposure during cooking $\left(\mu \mathrm{g} \cdot \mathrm{m}^{-3}\right)$} \\
\hline & \multicolumn{2}{|c|}{$\mathrm{PM}_{10}$} & \multicolumn{3}{|c|}{$\mathrm{PM}_{2.5}$} \\
\hline Verandah (biomass) & \multicolumn{2}{|c|}{264.81} & \multicolumn{3}{|c|}{128.18} \\
\hline Open air (biomass) & \multicolumn{2}{|c|}{380.9} & \multicolumn{3}{|c|}{249.35} \\
\hline Separate kitchen wthout ventilation (LPG) & \multicolumn{2}{|c|}{112.94} & \multicolumn{3}{|c|}{54.65} \\
\hline Separate kitchen wth ventilation (LPG) & \multicolumn{2}{|c|}{122.91} & \multicolumn{3}{|c|}{67.09} \\
\hline verandah (LPG) & \multicolumn{2}{|c|}{167.7} & \multicolumn{3}{|c|}{111.14} \\
\hline Multipurpose room (LPG) & \multicolumn{2}{|c|}{118.08} & \multicolumn{3}{|c|}{50.94} \\
\hline \multirow{2}{*}{ Type of kitchen with different fuel use } & \multicolumn{5}{|c|}{ Gaseous pollutants (ppm) } \\
\hline & $\mathrm{CO}$ & $\mathrm{CO}_{2}$ & $\mathrm{SO}_{2}$ & $\mathrm{NO}$ & $\mathrm{NO}_{2}$ \\
\hline Kitchen (biomass) & 3.34 & 509.71 & 0.07 & 0.10 & 0.03 \\
\hline Ventilated kitchen & 0.89 & 395.71 & 0.02 & 0.04 & 0.02 \\
\hline Non-ventilated kitchen & 0.9 & 401.71 & 0.02 & 0.04 & 0.02 \\
\hline
\end{tabular}

Source: Based on field survey, 2010.

type of fuel/stoves used and exposure to smoke and heat) and 3 (showing mean concentrations of SPM and gaseous pollutants in different kitchen locations using different types of fuels) we find that it is the lower income women who cook in a multipurpose room (31 percent of very low and 19 percent of low) which is not-ventilated (78 percent of very low and 43 percent of low) using biomass fuels/traditional chulhas (97 percent very low and 79 percent low) are highly exposed to the emitted pollutants. Monitoring of air pollutants (Table 3) results have shown that concentration of pollutants is maximum when cooking is done in a non-ventilated multipurpose room using biomass fuels/chulhas. Thus, the lower income women are most vulnerable.

\section{Symptomatic Linkages between Tuberculosis in Women Exposed to Domestic Cooking Fuels}

In this part an attempt has been made to examine the symptomatic linkages between tuberculosis in women and type of fuel used, cooking locations and type of house in which the respondents live. The self reported symptoms of tuberculosis includes persistent cough, continuous fever, phlegm, chest pain, haemoptysis (coughing of blood) and other symptoms like breathlessness, wheezing, sore throat, running nose etc (Table 4).

It has been observed that nearly 1069 households (51 percent of total sample; 97 percent of the very low, 79 percent of low, 6 percent of medium) were using biomass fuels/traditional stoves and 899 households (43 percent of the total sample) used LPG/gas stoves (100 percent high, 80 percent medium, 13 percent low and 3 percent very low) for cooking. The symptoms of tuberculosis have been found to be significantly higher among those using biomass fuels (17 percent reported of persistent cough, 17 percent of phlegm, 16 percent of chest pain, 13 percent of continuous fever, 7 percent of haemoptysis and 21 percent of other symptoms) as compared to those using LPG (4 percent reported of chest pain, 4 percent of persistent cough, 4 percent of phlegm, 3 percent of continuous fever, 2 percent of haemoptysis, 10 percent of other symptoms) (Table 4(a)). It has already been observed (Table 3) that the biomass emits higher levels of toxic pollutant $\left(\mathrm{SPM}, \mathrm{CO}, \mathrm{CO}_{2}, \mathrm{SO}_{2}, \mathrm{NO}, \mathrm{NO}_{2}\right.$ ) which poses greater health risks. Recently a review on state of indoor air quality has concluded that although the levels of indoor air pollution are considerably higher due to use of biomass fuels but it had not received much attention due to a lack of awareness among the population and policy makers regarding its association with ill health [14].

Similar analysis on the basis of self reported symptomatic cases of tuberculosis and kitchen locations (separate indoor kitchen, indoor kitchen in verandah, in multipurpose room and open air kitchen) shows that tuberculosis was found to be significantly higher among those cooking in multipurpose room (11 percent reported of chest pain, 10 percent of persistent cough, 9 percent of phlegm, 9 percent of continuous fever and 4 percent of haemoptysis, 28 percent of other symptoms), separate indoor kitchen ( 5 percent reported of persistent cough, 5 
Table 4. Symptomatic linkages of tuberculosis (in percentages) and fuel use, house type and kitchen location in the sampled households in Aligarh city (2008-2009). (a) Type of fuel used: Biomass and LPG; (b) Kitchen locations; (c) House type: Kutcha/semi-Pucca and Pucca houses.

(a)

\begin{tabular}{cccccccc}
\hline \multirow{2}{*}{\begin{tabular}{c} 
Type of fuel $\begin{array}{c}\text { No. of } \\
\text { used }\end{array}$ \\
\cline { 3 - 8 }
\end{tabular}} & \begin{tabular}{c} 
Touse-holds \\
\cline { 3 - 8 }
\end{tabular} & Persistent cough & Continuous fever & Phlegm & Chest pain & Haemoptysis (coughing of blood) & Other symptoms \\
\hline Biomass & 1069 & 16.92 & 12.92 & 16.60 & 16.25 & 6.68 & 21.15 \\
LPG & 899 & 4.23 & 3.23 & 4.00 & 4.34 & 1.67 & 9.69 \\
\hline
\end{tabular}

(b)

\begin{tabular}{|c|c|c|c|c|c|c|c|}
\hline \multirow[b]{2}{*}{ Cooking locations } & \multirow{2}{*}{$\begin{array}{c}\text { No. of } \\
\text { house-holds }\end{array}$} & \multicolumn{6}{|c|}{ Tuberculosis symptoms } \\
\hline & & Persistent cough & Continuous fever & Phlegm & Chest pain & $\begin{array}{c}\text { Haemoptysis } \\
\text { (coughing of blood) }\end{array}$ & Other symptoms \\
\hline Separate indoor kitchen & 992 & 4.94 & 4.44 & 4.03 & 4.74 & 1.20 & 7.56 \\
\hline $\begin{array}{l}\text { Indoor kitchen in } \\
\text { multipurpose room }\end{array}$ & 294 & 9.88 & 8.76 & 9.48 & 10.84 & 3.68 & 27.64 \\
\hline $\begin{array}{l}\text { Indoor kitchen in } \\
\text { verandah }\end{array}$ & 520 & 2.88 & 2.31 & 3.07 & 3.46 & 0.77 & 5.77 \\
\hline Open air kitchen & 295 & 2.03 & 1.35 & 2.37 & 2.71 & 0.67 & 4.41 \\
\hline
\end{tabular}

(c)

\begin{tabular}{cccccccc}
\hline & \multirow{2}{*}{$\begin{array}{c}\text { No. of } \\
\text { House type }\end{array}$} & \multicolumn{5}{c}{ Tuberculosis symptoms } \\
\cline { 3 - 8 } & households & Persistent cough & Continuous fever & Phlegm & Chest pain & $\begin{array}{c}\text { Haemoptysis } \\
\text { (coughing of blood) }\end{array}$ & Other symptoms \\
\hline Kutcha/semi-Pucca & 690 & 9.4 & 7.92 & 6.52 & 8.21 & 1.73 & 18.04 \\
Pucca & 1411 & 2.35 & 1.98 & 1.63 & 2.05 & 0.42 & 4.6 \\
\hline
\end{tabular}

Source: Based on field survey 2010-11.

percent of chest pain, 4 percent of continuous fever, 4 percent of phlegm, 1 percent of haemoptysis and 8 percent of other symptoms) as compared to those who cook in verandah ( 3 percent reported of chest pain, 3 percent of phlegm, 3 percent of persistent cough, 2 percent of continuous fever, 0.77 percent of haemoptysis and 6 percent of other symptoms) and in open air kitchen (3 percent reported of chest pain, 2 percent of phlegm, 2 percent of persistent cough, 1 percent of continuous fever, 0.67 percent of haemoptysis and 4 percent of other symptoms) (Table 4(c)). This is due to higher exposure to pollutants in case of indoor cooking as compared to that of open air cooking.

Similar analysis on the basis of self reported symptoms of tuberculosis and type of house of the respondents shows that tuberculosis was significantly higher among those living in kutcha/semi-pucca houses ( 9 percent reported of persistent cough, 8 percent of chest pain, 8 per cent of continuous fever, 7 percent of phlegm, 2 percent of haemoptysis and 18 percent of other symptoms) as compared to those living in pucca houses ( 2 percent of reported persistent cough, 2 percent of chest pain, 2 percent of continuous fever, 2 percent of phlegm, 0.42 per- cent of haemoptysis and 5 percent of other symptoms) (Table 4(b)). This was due to the fact that the construction material used for kutcha houses absorbs the emissions from cooking fuels causing longer period of exposure and many times the house remains damp posing health hazards. This was also due to poor ventilation and lower ceiling height in kutcha houses as compared to pucca houses. Moreover, the use of LPG, is higher among the residents (usually the higher income class) living in pucca houses.

Women exposed to indoor smoke are three times as likely to suffer from tuberculosis, than women who cook and heat with electricity, gas and other cleaner fuels [15]. A perusal of Table 5 and Figure 2 shows the incomewise distribution of the sampled women respondents according to the unhealthy cooking conditions (use of biomass fuels/chulhas, cooking in non-ventilated multipurpose room, living in kutcha/semi pucca houses) and the occurrence of tuberculosis. Of the total sample nearly 25 percent of the very low income women, 19 percent of the low and 6 percent of the medium income women reported of suffering from tuberculosis. The prevalence of tuberculosis amongst women using LPG and cooking 


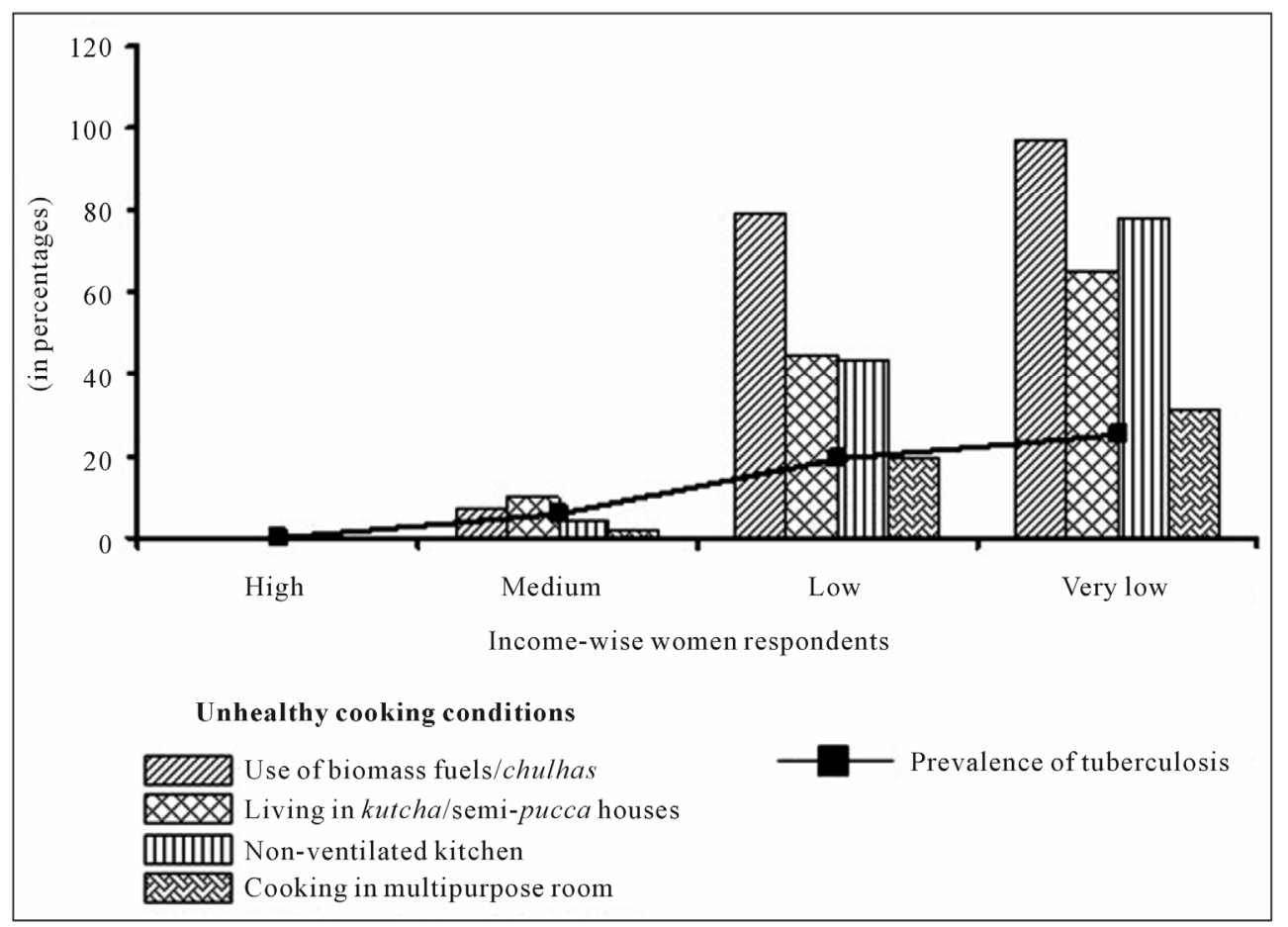

Figure 2. Unhealthy cooking conditions and prevalence of tuberculosis in women.

Table 5. Unhealthy cooking conditions and prevalence of Tuberculosis (in percentages) in Indian women.

\begin{tabular}{cccccc}
\hline \multirow{2}{*}{$\begin{array}{c}\text { Income-wise women } \\
\text { respondents }\end{array}$} & $\begin{array}{c}\text { Use of biomass } \\
\text { fuels/chulhas }\end{array}$ & $\begin{array}{c}\text { Cooking in } \\
\text { multipurpose room }\end{array}$ & $\begin{array}{c}\text { Non-ventilated } \\
\text { kitchen }\end{array}$ & $\begin{array}{c}\text { Living in } \\
\text { kutcha/semi-pucca houses }\end{array}$ & $\begin{array}{c}\text { Prevalence of } \\
\text { tuberculosis }\end{array}$ \\
\cline { 2 - 6 } High & - & - & - & - & - \\
Medium & 7 & 2 & 4 & 10 & 6 \\
Low & 79 & 19 & 43 & 44 & 65 \\
Very low & 97 & 31 & 78 & 33 & 25 \\
Total & 51 & 14 & 25 & & 22.79 \\
\hline
\end{tabular}

Source: Based on field survey 2010-2011.

in a separate kitchen and living in pucca houses was almost negligible. None of the high income women respondent reported of suffering from tuberculosis. In households where unhealthy cooking conditions exist, the women face the risk of tuberculosis. The prevalence of tuberculosis is 3.6 times higher in households using biomass fuels than in households using LPG, 2.6 times higher in households cooking in multipurpose room than in households cooking in separate kitchen and 3.9 times higher in households living in kutcha/semi-pucca houses than in households living in pucca houses.

The analysis revealed that women are more vulnerable in houses using biomass fuels which emit poisonous pollutants cooking in non-ventilated multipurpose room and living in kutcha/semi pucca houses which retains the pollutants for a longer duration. In such conditions the risk of tuberculosis has increased many folds. This revelation is along expected gender bias as women are more exposed to cooking smoke in India.

\section{Conclusions}

The study provides evidence that the use of biomass fuel for cooking is a risk factor for tuberculosis. Irrespective of the evidence for associations between indoor biomass use and tuberculosis, it is clear that cooking fuel produces substantial indoor air pollution with health damaging gaseous pollutants and particulate matter. Monitoring the air quality revealed that the concentration of gaseous and solid pollutants was maximum when cooking was done in non-ventilated, multipurpose room using biomass fuels and mostly the lower income women were 
found cooking at such kitchen locations. In addition to this the lower income women were found residing in sub-standard dwellings without proper ventilation. All such dilapidated living conditions and use of traditional biomass fuels leads to rigorous exposure to the indoor toxic pollutants. Thus, the lower income women were most vulnerable to indoor air pollution. The linkages between different type of fuel used, kitchen locations and house type with occurrence of tuberculosis is physically rational and dependable, as in the non-ventilated, multipurpose room the toxic pollutants get concentrated and remains inside for longer duration. Similarly the construction material of kutcha/semi-pucca houses absorbs the pollutants for longer duration thus increasing exposure duration which enhances the possibility of occurrence of several diseases. Crowding in home is also a major catalyzing factor for occurrence and spread of tuberculosis, as it is a communicable disease which spreads with respiratory contact.

Thus it can be said that the indoor air pollution is a risk factor for TB which is exacerbated by other related living conditions. Women being involved in cooking, work for long duration is most vulnerable. To avoid the harmful effects of indoor air pollution, households should be encouraged to move up the energy ladder.

\section{REFERENCES}

[1] K. R. Smith, "The National Burden of Disease in India from Indoor Air Pollution," Proceeding National Academy of Science, Vol. 97, No. 24, 2000, pp. 13286-13293. doi:10.1073/pnas.97.24.13286

[2] E. Duflo, M. Greenstone and R. Hanna, "Indoor Air Pollution, Health and Economic Well Being," Mendeley, Vol. 1, 2008, pp. 1-9.

[3] Census of India, "Registrar General and Census Commissioner," 2001

[4] J. R. Boelaert, M. S. Gomes and V. R. Gordeuk, "Smok- ing, Iron, and Tuberculosis," Lancet, Vol. 362, No. 9391, 2003, pp. 1243-1244.

doi:10.1016/S0140-6736(03)14529-1

[5] M. N. Bates, A. Khalakdina, M. Pai, L. Chang, F. Lessa and K. R. Smith, "Risk of Tuberculosis from Exposure to Tobacco Smoke: A Systematic Review and Meta-Analysis," Archives of Internal Medicine, Vol. 167, No. 4, 2007, pp. 335-342. doi:10.1001/archinte.167.4.335

[6] H. H. Lin, M. Ezzati and M. Murray, "Tobacco Smoke, Indoor Air Pollution and TB: A systematic Review and Meta-analysis," PLoS Medicine, Vol. 4, No. 1, 2007, pp. 4-20.

[7] K. R. Smith, "Biofuels, Air Pollution and Health," Plenum Pres, New York, 1987.

[8] V. K. Shalini, M. Luthra, L. Srinivas Rao, S. Basti and M. Reddy, "Oxidative Damage to the Eye Lens Caused by Cigarette Smoke and Fuel Smoke Condensates," Indian Journal of Biochemistry \& Biophysics, Vol. 31, No. 4, 1994, pp. 261-266.

[9] P. Kulshreshtha, M. Khare and P. Seetharaman, "Rural Energy and Health impacts," Indoor Air, Vol. 18, No. 6, 2008, pp. 488-498. doi:10.1111/j.1600-0668.2008.00550.x

[10] National Family Health Survey (NFHS-3), "International Institute for Population Sciences (IIPS) and Macro International," 2007.

[11] H. L. Rieder, "Epidemiologic Basis of Tuberculosis Control," International Union Against Tuberculosis and Lung Disease, Paris, 1999.

[12] World Health Organization, "Tuberculosis," 2010.

[13] K. Park, "Prevention and Social Medicine," Banarsidas Bhanot Publisher, Jabalpur, 2007.

[14] I. Colbeck, Z. A. Nasir and Z. Ali, "The State of Indoor Air Quality in Pakistan-A Review," Environmental Science and Pollution Research, Vol. 17, No. 6, 2010, pp. 1187-1196. doi:10.1007/s11356-010-0293-3

[15] World Health Organisation, "Indoor Air Pollution and Household Energy Monitoring," Workshop Resource, Geneva, 2005. 